\title{
INVENCIÓN DE LA MEMORIA Y FICCIÓN EN LA NARRATIVA LOCAL DEL CARBÓN, PRODUCIDA A MEDIADOS DEL SIGLO XX: MUNDO LABORAL Y SOCIAL
}

\author{
Juan Bahamonde Cantín \\ Universidad del Bío-Bío, Concepción, Chile \\ jbahamon@ubiobio.cl
}

\section{RESUMEN / ABSTRACT}

Artículo vinculado al área de la narrativa literaria de la cuenca del carbón de la Región del Biobío (posterior a Baldomero Lillo), considerando dos novelas: Hijo de la piedras (1963) de Juan Sánchez Guerrero y Una huelga en el carbón (1965) de Guillermo Pedreros, y cuatro cuentos: "Ratonera" (1962-63) de José Chesta, "El ratón de cada uno" (1992) de Alfonso Alcalde, "Trasto viejo" (1991) de Víctor Hugo Gómez y "Tren a Río Pedregoso" (2001) de Miguel Ramírez. Estas obras, producto de la invención de la memoria y la ficción, pertenecen a una de las vertientes creativas como son los autores locales: mineros, dirigentes gremiales, escritores aficionados y reconocidos en el mundo intelectual. A nivel genérico, los textos novelescos se inscribirían en la propuesta de un estudioso del género "memorias" en Chile: Leonidas Morales (2001 y 2013); en cambio, los cuentos se adscriben plenamente en la ficcionalidad literaria.

En el artículo se analizan, primeramente, temáticas del "realismo social" o crítica social, acontecidas a mediados del siglo XX, que predominan en los cuatro cuentos seleccionados $\mathrm{y}$, en segundo lugar, se examinan temas sociales, laborales y sindicales, que se evidencian en las dos novelas, asociados a la "cuestión social" (inicios del XX).

PALABRAS Clave: vertiente creativa local, narrativa del carbón, realismo social, "cuestión social".

The InVENtion of Memory and Fiction in the Local NarRative Literature of Coal Produced in the MiddLe of the Twentieth Century: Working and Social WorldS

This article deals with the literary narrative of the coal valley located in the Bio Bio Region (after Baldomero Lillo), considering two novels: Hijo de las piedras (1963) by Juan Sánchez Guerrero and Una huelga en el carbón (1965) by Guillermo Pedreros and four short stories: 
"Ratonera" (1962-63) by José Chesta, "El ratón de cada uno" (1992) by Alfonso Alcalde, "Trasto viejo" (1991) by Víctor Hugo Gómez and "Tren a Río Pedregoso" (2001) by Miguel Ramirez. These works, a product of the invention from memory and fiction, can be classified within the creative group known as local authors: miners, union leaders, amateur writers well-known in the intellectual world. The novels can be classified within the genre "memories" in Chile, proposed by the scholar Leonidas Morales (2001 and 2003); on the other hand, the short stories are widely classified as literary fictionality.

This article analyses, first, topics from "social realism" or social criticism associated with events which took place in the middle of the twentieth century, and also which predominate in the four chosen short stories and secondly, social, labor and union topics are examined, which are evident in both novels, linked to the "social issue" (beginning of the twentieth century).

KEYWORDS: local creativity, coal narrative, social realism, "social issue".

Recepción: 28/04/2017

Aprobación: 08/08/2017

\section{A MANERA DE ANTECEDENTE}

El año 1852 marcó el nacimiento de la industria carbonífera de la Región del Biobío, impulsada por don Matías Cousiño, que paulatinamente fue dando origen a explotaciones carboníferas en otras ciudades de la Región. Estos yacimientos originaron una tradición del obrero del carbón con su folclore y su condición social. Pero no será sino hasta con Baldomero Lillo que se registrará solo tangencialmente la "cuestión social" del carbón cuando en 1904 se publiquen los "cuadros mineros" de Sub-terra1. Pero la "cuestión social" no es simplemente una cuestión literaria. Entre los años 1902 y 1926 -según G. Grez (1997)-,los mineros comienzan a organizarse en Sociedades de Socorros Mutuos $^{2}$. Solo en 1926 se forma el primer sindicato de mineros, el que con posterioridad se llamó Sindicato de Trabajadores $\mathrm{N}^{0}$ 6, que comprendía a obreros de Lota y Coronel. Desde esa fecha comenzó la larga y dura lucha del sindicalismo por conquistar mejores condiciones de vida, lo que se tradujo,

\footnotetext{
Nicomedes Guzmán, apoyándose en la información de José Santos González Vera, manifiesta que Baldomero Lillo publicó la primera edición de Sub terra en 1904 y la segunda edición, en 1917 (11).

2 Al respecto, en mayo de 1902 se fundó la Federación Mancomunal de Trabajadores de Lota y Coronel (60).
} 
primero, en la organización de motines (medidas de protestas) y, luego, en extensas y confrontadas huelgas (movimientos sociales).

Coincidentemente, desde la capital, el cuento "El finado Valdés" (1929) de Mariano Latorre recoge desde la ficción el desentendimiento por parte del Estado y las autoridades de la real explotación y los reiterados abusos perpetuados a los obreros de las minas de carbón ${ }^{3}$. Pero solo a mediados de los años 1960, esta situación aparece en la literatura de la cuenca del carbón, representada por escritores nacionales y regionales. Este artículo solo da cuenta de la producción de la segunda agrupación.

Ahora bien, en el plano político-social, en diciembre de 1970, durante el gobierno del presidente Salvador Allende, se produce la estatización de las empresas carboníferas. Sin embargo, entre los años 1975 y 1976, el Gobierno Militar determinó pasar todos los yacimientos a ENACAR, S.A. y, al mismo tiempo, se eliminaron los sindicatos de obreros y los dirigentes gremiales pasaron a un receso obligado. No obstante, en 1990, al regreso de la democracia a nuestro país se produce otra situación: el gobierno democrático de Patricio Aylwin inicia las gestiones para el cierre de los yacimientos, a través de la Ley de Reconversión (1993). Finalmente, el año 1997, durante el gobierno de Eduardo Frei Ruiz-Tagle, terminan definitivamente las actividades fabriles. Tales son los antecedentes preliminares de este artículo ${ }^{4}$.

\section{LA VERTIENTE CREATIVA LOCAL: ASPECTOS GENÉRICOS Y TEMÁTICOS PREDOMINANTES}

La agrupación temática de este artículo constituye un segmento social portador de una estética literaria relacionada con el mundo social, laboral y sindical de los yacimientos carboníferos de la Región del Biobío, prácticamente desconocida. Se trata de dos novelas y cuatro cuentos de autores locales de

3 Hay que considerar que la primera edición del cuento "El finado Valdés" apareció en el libro Chilenos y el mar (1929) y, posteriormente, el año 1947, en Chile, país de rincones (12).

Según J. Bahamonde (2013), entre los años 1994 y 1997, los centros mineros de Coronel y Lota dejaron de funcionar (14). Actualmente opera en Curanilahue la mina "Santa Ana" (ex "Chulita"); además, en esa misma localidad existe la explotación de pirquenes (minas artesanales). 
mediados y fines del siglo XX (posteriores a Baldomero Lillo), residentes en Tomé, Concepción, Lota y Curanilahue, preferentemente, que permanecen en el olvido, rescatadas en los archivos de la Biblioteca Nacional, bibliotecas universitarias y archivos locales. En este circuito literario participan mineros, dirigentes gremiales de las agrupaciones obreras, narradores aficionados y escritores acreditados especialmente en los espacios universitarios, como Alfonso Alcalde y José Chesta ${ }^{5}$, cuyas creaciones ficticias se inscriben de acuerdo a los preceptos canónicos como textos narrativos institucionalizados ${ }^{6}$.

Estos autores locales cuyas temáticas han acontecido a inicios y mediados del siglo XX, época de la efervescencia social de la industria carbonífera, se inscriben en el estatuto de lo enunciable y de lo visible propuesto por Deleuze $(1987)^{7}$, sobre la base de hechos socio-históricos propios de su época. Por lo tanto, como creadores, se inscriben en una postura que asigna a la literatura una función social; en palabras de Cedomil Goic: “[...] en activismo tendiente a promover cambios en la conciencia política -y a formarla- mediante la exposición de ciertos motivos y personajes y de motivaciones tendenciosas" (256).

2.1. Pues bien, las novelas consideradas en este artículo son producto de la invención de la memoria ${ }^{8}$, y se inscriben, genéricamente, una de ellas como discurso testimonial (referencial) y la otra como autobiografía. A nivel temático, estos textos aluden a una realidad laboral y social, dando cuenta de un acontecer en la literatura, que evidencia problemáticas del mundo minero antes que el Estado. Los autores, en su condición de obreros (un

5 Me refiero a José Chesta y Alfonso Alcalde, ambos valorados en el seno de la Universidad de Concepción. Marta Contreras y otros estudiosos analizan la producción literaria del primero en José Chesta. Textos y contextos. Por su parte, Gonzalo Rojas rinde tributo a Alcalde en el prólogo del libro Alfonso Alcalde en Cuento. Antología (8).

$6 \quad$ I. Carrasco manifiesta al respecto (2005):"Son textos que han pasado por los procesos de canonización...que consiste en la validación de un libro y/o autor mediante reseñas, artículos, comentarios, incorporación [...] en libros de texto, historias literarias [...] hasta conformar una imagen pública, estable y positiva..." (34).

Deleuze los denominaba "géneros menores". Ver artículo "Géneros referenciales: identidad y comunidad" de Leonidas Morales (124).

J. M. Fierro en su Tesis doctoral (2005) sistematiza en el contexto chileno varios géneros de la memoria, dice al respecto: "En el ámbito discursivo entenderemos por memoria la manera que tiene un ser humano de narrar o exponer su recuerdo, evocación, interpretación y reproducción de experiencias pasadas y/o vividas" (31). 
extrabajador y un exdirigente gremial), narrativizan con auténtico realismo su pasado laboral y sindical, de inicios del siglo XX, época de pleno apogeo de la industria del carbón. En otras palabras, estas obras constituyen verdaderas páginas de denuncia del despertar de una conciencia colectiva, de la memoria de la infancia y juventud de sucesos acontecidos en los inicios del siglo XX. Son expresiones que transmiten la sensibilidad del trabajador minero (niño y adulto), sometido y explotado en las galerías subterráneas, pero también evidencian las primeras intenciones de movimientos sociales (huelgas), mediante la organización sindical.

a) Hijo de las piedras (1963), tercera novela de Juan Sánchez Guerrero, ambientada en Lota con prólogo del eminente crítico chileno, Juan Loveluck, quien lo cataloga (o encasilla) genéricamente como texto en el que "predomina el tejido autobiográfico poetizado" (11) ${ }^{9}$. Es un relato que apela-según J. M. Fierro- a la autobiografía, por cuanto aborda "desde la perspectiva del yo, capítulos sobre circunstancias de una historia individual [...] determinada por quiebres o situaciones límite a los cuales el narrador se ve sometido" (43). De esta manera el exminero de Lota, en su condición de sujeto individual y víctima de la misma situación, reconstituye a través del recuerdo la sacrificada vida como niño-trabajador (tema recurrente en la narrativa del carbón), desde su triste y penosa orfandad a su prematuro y forzado trabajo, primero a los siete años como plantador de pino y luego a los diez años, como minero en el interior de los oscuros y frágiles socavones, desde donde fortuitamente escapa de un accidente fatal que lo obliga a alejarse para siempre ${ }^{10}$. En sus labores en el interior de la mina de Lota, el niño Omar es apoyado por el "padrino", apodado "El Amigo", quien le entrega los primeros consejos prácticos para habituarse en los oscuros laberintos subterráneos ${ }^{11}$.

9 Sánchez Guerrero se reveló, anteriormente, como escritor con dos novelas: Proceso y Celda 13 (1).

10 Hay que considerar que este motivo del niño-minero se amparaba en un aspecto de orden cultural, la familia consideraba que el trabajo en los socavones era parte del mecanismo de preparación para la vida. Además, el vigor, la fuerza, la resistencia física adquirida tempranamente, daban certeza de que por esa vía los niños se "hacían hombres". Véase Jorge Rojas (405).

El tema del padrino protector del niño huérfano también prevalece en la novela Viento negro (1960) del médico Juan Marín. 
A nivel temático, también en la obra se evidencia el personaje de la mujer menoscabada, viuda de minero quien debe lidiar con mucho esfuerzo en la superficie de la mina, para la supervivencia de su familia. Celmira, junto a Omarcito, su pequeño hijo, debe resistir el trabajo de carretero fletador; de esta manera ampara a su familia del desalojo de la miserable habitación aportada por la compañía. El trabajo de cargar y descargar la carreta tirada por bueyes la maltrata tanto, físicamente, que paga con su vida dejando a su niño huérfano y desamparado.

Como tema secundario, la novela entrega matices de las primeras intenciones de organización sindical. (Esta temática será abordada más adelante en el contexto de la "cuestión social").

En suma: la novela de Juan Sánchez Guerrero es a nivel autobiográfico -en palabras de Fierro- la evocación, interpretación y reproducción de experiencias vividas y sufridas en carne propia por el narrador-personaje, a inicios del siglo XX, cuando la industria carbonífera se encontraba en pleno apogeo. A nivel literario representa simbólicamente a un grupo social marcado desde su nacimiento por la marginación laboral, social y educacional, como aconteció con los niños explotados en la industria del carbón de la Región del Biobío, a comienzos y mediados del siglo $\mathrm{XX}^{12}$.

b) Por su parte, Una huelga en el carbón (1965) es la primera producción literaria de Guillermo Pedreros ${ }^{13}$. Este dirigente gremial se detiene en su comprometida vida política, a los 61 años, para plasmar este libro, donde narra detalladamente la "Huelga grande del carbón de 1920", suceso en el que

12 La legislación social que se dictó en 1924 prohibió el trabajo subterráneo de los niños menores de 18 años; no obstante, en 1947, durante la agitación huelguística, la presencia de muchachos trabajadores en el interior de las minas volvió a ser denunciada. Véase Jorge Rojas (403-404).

13 Guillermo Pedreros es un autor ocasional, más bien reconocido a nivel nacional como dirigente gremialista. No obstante, con posterioridad, el año 1970, publicó otro libro: Huenchupil agitador profesional, publicado en Santiago por Prensa Latinoamericana. En el prólogo de esta segunda publicación, Vicente Poblete define este texto como "verdadero tratado didáctico novelado [...] que debe ser leído por los dirigentes que recién se inician en la lucha de los trabajadores organizados" (8). 
participó activamente ${ }^{14}$. Se circunscribe genéricamente a "las memorias"15, pues la obra reconstruye un momento importante de la historia gremial, sindical y cultural de la zona carbonífera ${ }^{16}$. En otras palabras -siguiendo a L. Morales- el autor-narrador tiene conciencia de la importancia de su testimonio para la sociedad en que vive y, por lo tanto, su función es la de informar, comunicar, recrear hechos acontecidos, con los recursos no siempre imaginarios del lenguaje, aunque sea el de la no ficción.

Ahora bien, Morales, en un trabajo posterior (2013), plantea una división en tres períodos para los géneros de la "memoria" que son coherentes con tres momentos históricos de nuestro país ${ }^{17}$. El tercer y último período es fundamental, porque aquí es donde se encasilla Una huelga en el Carbón (1965). Se caracteriza porque los memorialistas "instalan una memoria de la diferencia, política, social y culturalmente [...]. Los nuevos memorialistas terminan también con la centralidad de Santiago" (21). En otras palabras, es una memoria que se instala en una postura combativa hacia el poder dominante.

Según Guillermo Pedreros, la cuenca del carbón es un volcán a punto de estallar. El movimiento huelguístico se inicia por las arbitrariedades de "Mr. Hyde", un administrador de Lirquén que reduce arbitrariamente los jornales de los mineros; además, despide y desaloja de sus casas a quienes manifiesten desagrado. Por otro lado, la intención ética que tiene Guillermo Pedreros como testigo es en particular, "rendir un homenaje a las mujeres,

$14 \quad$ En el prefacio de Una huelga en el carbón (1965), Jorge Barría Serón expresa que "Guillermo Pedreros es el obrero autor de esta obra. Desde muy joven se desempeñó como trabajador de los Arsenales de Marina de Talcahuano. Se encontraba laborando ahí cuando ayudó a fundar el Centro de Estudios Sociales "Artes y Emancipación" al que le cupo actuar en la huelga, objeto de su narración...A la lucha sindical se une su militancia política como uno de los fundadores del Partido Obrero Socialista, en Talcahuano [...] terminando por ingresar y militar activamente hasta hoy día en el Partido Socialista de Chile" (9).

15 Leonidas Morales (2001) denomina texto referencial o "la escritura de al lado" cuando discursivamente el autor y el sujeto de la enunciación (o "narrador") coinciden, son el mismo (11).

16 En palabras de J. M. Fierro (2005), Una huelga en el carbón “" ...] es verdaderamente un tiempo vivido, experimentado, socialmente compartido, el que se rememora o se evoca. Allí reside el material que la memoria procesa y recrea..." (40).

$17 \quad$ El primero se caracteriza por sujetos públicos preocupados por la conformación de una identidad nacional como Vicente Pérez Rosales con Recuerdos del pasado (1814 - 1860). El segundo período contempla las dos últimas décadas del siglo XIX y las primeras del siglo XX, donde destacan obras por la imitación del modelo de belleza francés aburguesado. Una obra destacada es Memorias de 50 años (1908) de Ramón Subercaseaux (16-21). 
que fueron verdaderas heroínas de estos acontecimientos sociales de la época" (16). El autor, situándose como un sujeto que presenció los hechos en contraste con los dirigentes sindicales, intenta corregir la situación de olvido y subordinación intrínsecos al discurso femenino. De esta manera, especifica en el prólogo del libro: "Quise hacer justicia, a un hecho que estimo, nos hemos olvidado [...], me refiero a la participación que las mujeres han tenido en el movimiento social o gremial " (6).

El texto, al mismo tiempo, posee una belleza estética: apunta a un contenido politizado y un desarrollo a través de un hito histórico. Las informaciones y las voces complementarias abundan en forma de poemas "Es horrible vivir, es horrible habitar/ En la tierra de crueles burgueses;/ Donde solo se sabe sufrir/ Donde solo se sabe explotar" (28). Así también existen cantos, himnos, noticias y textos comunicacionales reveladores, como el telegrama dirigido al secretario general de la Federación Obrera de Chile, compañero Enrique Díaz Vera, que dice: “Administrador carbonífica de Lirquén, (sic) provocó movimiento huelguístico separando personal. Afrontaremos situación. Valdés, Presidente" (21).

Por otra parte, el autor utiliza recursos lingüísticos objetivos y subjetivos. Pretende la objetividad, por ejemplo, al mantener el uso de verbos impersonales. Sin embargo, hay pequeños fragmentos que lo incluyen dentro de su emocionalidad y, al mismo tiempo, revelan a Pedreros dentro de la narración y la subjetividad; dice: "Todos hemos gozado con el espectáculo que nos ha brindado Carmen Serrano. Hubiéramos estado toda la noche escuchando sus interpretaciones" (32). Por lo tanto, se genera una narrativa desde el plano subjetivo del recuerdo y la experiencia.

Finalmente, Pedreros escribe Una huelga en el carbón en base a su experiencia personal, al participar activamente en la "Huelga grande del carbón de 1920". Él es un testigo, pero su relato se aleja del discurso y se acerca más al género "memoria". Para configurar su historia como un todo coherente, la divide en capítulos temáticos breves, apoyado en múltiples tipos de discursos: textos poéticos musicales, administrativos (como el telegrama señalado más arriba) y periodísticos, que forman parte sustancial de su relato. De esta forma, la literatura es capaz de representar acontecimientos históricos reales; sin embargo, entre mayores sean los elementos estéticos, se aleja cada vez más de lo referencial.

En definitiva, como discurso esta obra puede ser considerada literatura. En el inicio se presenta a Lota, metafóricamente, como "un volcán a punto de estallar”. El desarrollo se tensiona entre la organización/acción obrera contra 
los actos represivos que los mineros sufren; un claro ejemplo es el actuar del líder Guillermo Vidal al enfrentarse verbalmente con los administradores y gerentes de la compañía. La conclusión es el triunfo de la huelga (reducción de la jornada de trabajo, eliminación de la policía privada y aumento salarial) y la concurrencia masiva de los trabajadores y sus familiares a la cancha de fútbol, con un arco transformado en tribuna y adornado de copihues rojos, desde donde los dirigentes de la FOCH informaron de "la gran victoria". Finalmente, el epílogo del libro es la muerte de Delfina González (gran líder de este movimiento de 1920) y su despedida final ${ }^{18}$.

2.2. Se han seleccionado cuatro cuentos de escritores regionales, nacidos a comienzos y mediados del siglo XX. Se trata de textos perteneciente a una vertiente más ficcional, elaborados con mayor creatividad y atentos a un lector más reflexivo. A nivel temático, los cuatro textos intentan elevar a la dignidad estética temas sociales que persisten en forma reiterativa en el mundo de la explotación de los yacimientos carboníferos, de mediados y fines del siglo XX: "El ratón de cada uno" del reconocido poeta, narrador y periodista, avecindado en Concepción y Tomé, Alfonso Alcalde (1921-1992); "Ratonera" del recordado dramaturgo penquista, José Chesta (1936-1961); "Trasto viejo" del minero lotino aficionado a la escritura, Víctor Hugo Gómez (nació en Lota, 1948) ${ }^{19}$ y "Tren a Río Pedregoso" del escritor local avecindado en Lebu, Miguel Ramírez (quien nació en Curanilahue, 1944). Estos cuatro relatos se inscriben en la denominada narrativa regional y local de mediados del siglo XX (más precisamente lo que podría denominarse "narrativa del carbón de mediados y fines del siglo XX").

En general, estos escritores locales -en palabras de Cedomil Goic (1960: 254)- optan por los procedimientos del "realismo social" (más bien definido como crítica social), hasta convertir la literatura en expresión de clase". Por lo tanto, podrían insertarse en la historia de la literatura hispanoamericana dentro de la descripción global que hace Goic cuando señala que "[u]na tendencia secundaria corre paralelamente a lo largo de la literatura contemporánea poniendo

18 Parte de esta información está extraída de la Tesis de pregrado de Felipe Morales Carrasco, dirigida por el autor de este artículo (2016).

19 El cuento "Trasto viejo" ha sido extraído del libro Antología del cuento minero chileno (301-305). 
el acento en la cercanía del contexto histórico, político, económico y social, en oposición a la dominante antirrealista de la literatura contemporánea" ${ }^{20}$.

a) En primer lugar, la versión del cuento "El ratón de cada uno" (publicado en 1992) pertenece a Alfonso Alcalde, quien gran parte de su vida, aunque en forma intermitente, residió en la Región del Biobío, principalmente en las ciudades de Concepción, Lota y Tomé (más precisamente en Coliumo); justamente en este último lugar, solitario y con problemas en la visión, concibe materializar su final trágico el 5 de mayo de $1992^{21}$. En su condición de escritor, Alcalde miró, observó y recreó, empapándose vivencialmente de la vida minera. Así, primero en Reportaje al carbón (1973) escarbó en los recuerdos las historias narradas por los propios mineros, sus mujeres, sus dirigentes y sus técnicos ${ }^{22}$. En palabras del propio Alcalde: “...este reportaje es el testimonio de una larga lucha colectiva, el desafío de hombres, mujeres y niños que después de ser casi esclavos lograron emanciparse [...] a través de la organización política, consciente y responsable" $(5)^{23}$.

Ahora bien, en el desarrollo del relato "El ratón de cada uno", cuyos personajes (Periodista y Minero) son pasajeros que dialogan en un microbús del recorrido Concepción-Coronel-Lota, se evidencia, en primer lugar, un rasgo social relevante en la literatura del carbón producida a mediados del siglo XX: "la ausencia de individuación". Los obreros de los socavones carecen de nombres propios, de proyectos de vida y de realización personal; por lo tanto, son privados de los derechos del hombre y del ciudadano. En otras palabras, en el interior de las galerías subterráneas los numerosos grupos de obreros que trabajaban en los frentes de explotación no son tratados por los mayordomos como seres humanos, sino como anónimos. A los administradores no le interesan los problemas, las cualidades y virtudes individuales de cada minero, sino solo valoran el rendimiento en el trabajo, esto es, la cantidad de carbón extraído en el turno.

20 Cit. en Marta Contreras et al. (40).

21 A este respecto, Gonzalo Rojas dice en el prólogo "Invitación a leer a Alfonso Alcalde: “Amó a Concepción y a su gente. Concibió esa pasión afrontando riesgos. De hecho, su desaparecimiento terrible ocurrió en Tomé..." (8).

22 Libro de Editora Nacional Quimantú del gobierno de la Unidad Popular.

23 Cristian Geisse Navarro (2007) destaca la cantidad de oficios que Alcalde desempeñó durante diversos períodos de su vida: "En distintos lugares el escritor señaló haber trabajado como "picapedrero, minero, ayudante panificador, vago consuetudinario" (21). 
Precisamente, este rasgo asociado a la discriminación social se constata en el relato de Alcalde, delatado por el minero que viaja en el bus de Concepción a Lota: "Yo tengo la ficha $\mathrm{N}^{\mathrm{o}} 2.126$... Nadie habla de humanos, sino de números. En este instante, el 748 está enfermo, el 2.356 fue padre otra vez, el 3.779 anda en las tomas" (171). En otras palabras, en el texto cada ficha singulariza a un obrero, que es tratado como un objeto destinado a una acción u operación dentro de la mina, pero despojado de sus derechos.

En segundo lugar, a nivel temático, como antiguamente no existían baños en el interior de las minas, el ratón era el "sanitario" que limpiaba las galerías. Al mismo tiempo, los roedores, especie de vigilantes naturales, ejercían un importante papel relacionado con la supervivencia en el interior de las galerías subterráneas, puesto que escapaban ante la presencia del gas grisú, alertando a los mineros del mortal "viento negro". Esta última situación asociada a la seguridad permitía una estrecha sinergia entre el roedor y el trabajador quien no solo lo alimentaba, sino que, al mismo tiempo, respetaba una especie de ordenanza interna que prohibía su eliminación ${ }^{24}$. La sensibilidad de Alcalde permite percibir en su hermoso relato esta estrecha relación obrero-animal:

Se produce, ¿cómo decirlo?, una especie de amistad, entre el animal y el que saca las piedras de carbón; se conocen desde lejos en la oscuridad $[\ldots]$ Hacen un trabajo como cualquier otro y le pagan menos que lo que ganan $[\ldots]$ Hay, además, un acuerdo de organización $[\ldots]$ En el que cada compañero tiene que cuidar su rata para proteger la salud de los demás... (172-173).

El relato de Alcalde permite determinar que en el interior de los chiflones, donde los obreros trabajan en condiciones infrahumanas, los gerentes tienen el poder sobre la vida y la muerte de sus trabajadores, a quienes prácticamente menosprecian como personas.

b) En segundo lugar, la versión del cuento "Ratonera", publicado en la revista Vanguardia (1962-63)25, pertenece a José Chesta (1936-1961), escritor relevante para la actividad cultural y teatral de los años sesenta en Concepción. La producción narrativa y teatral de Chesta ha sido rescatada y

$24 \quad$ Ver al respecto el artículo (2013) de Juan Bahamonde Cantín (200-201).

25 El cuento "Ratonera" fue publicado en la revista Vanguardia, en Concepción, en ediciones a mimeógrafo durante los años 1962-63. Ver Marta Contreras (29). 
estudiada por Marta Contreras y otros $(1994)^{26}$. El relato evidencia el tema del "niño huérfano, abandonado", muy recurrente en la narrativa del carbón, pero ahora no en el contexto del interior de la mina, sino en la superficie; esto es, en la cotidianeidad del asentamiento industrial de Coronel, de mediados del siglo $\mathrm{XX}^{27}$.

Ahora bien, retomando el relato de José Chesta, Ratonera es el seudónimo de un niño maltratado, cuya mandíbula inferior, pequeña y puntiaguda, semejaba a un ratón. Hijo de una madre alcohólica, criado sin padre. Como niño huérfano de minero trabajó en el interior de la mina, donde producto de un accidente perdió parte del pie, por lo cual cojea.

El relato rescata la sensibilidad del infante que, a pesar de su penuria y deformidad física, se siente satisfecho por las nobles acciones sociales que es capaz de realizar: es obediente, sumiso, cortés (ejecuta los mandados de las vecinas de Villa Mora en Coronel). Además, Ratonera es fiel y responsable como hijo: se preocupa de su madre alcohólica, a quien con frecuencia debe librar del cuartel policial donde es apresada ${ }^{28}$. Pero en su condición de niño marginado, también goza de la picardía y la infamia; es así como en el contexto de las festividades del "18 de Septiembre", e impulsado por la curiosidad, logra la detonación de un cañón viejo que encuentra abandonado en el patio de un vecino.

c) En tercer lugar, el cuento "Trasto viejo", producto de la invención de la memoria, ha sido rescatado de la Antología del cuento minero chileno (1991). Pertenece al exminero lotino aficionado a la escritura de relatos narrativos y líricos (inéditos), Víctor Hugo Gómez, quien trabajó siendo muy joven como apir, barretero y otros oficios, hasta ejercer labores de mantención en las galerías de Revuelta ${ }^{29}$.

A nivel temático, relata la historia de un viejo minero, conocido entre los obreros como don Pedrito, quien se encuentra físicamente gastado,

26 Los estudiosos de la obra de José Chesta, como Marta Contreras y otros, consideran que sus obras están llenas de un "color local" (11).

27 Tema tratado también por el estudioso Ignacio Álvarez (109).

28 Según Marta Contreras, el relato de Chesta, ambientado en Coronel, "rescata un tipo de circulación de la pobreza por medio de la cual se salva la dignidad humana de los personajes y se insta al lector a entrar en una relación de conocimiento y compasión con ellos" (30).

29 Víctor Hugo Gómez nació en Lota el año 1947. Estudió la especialidad de minas en la Universidad Técnica del Estado, sede La Serena, carrera que no terminó (301). 
deteriorado y psicológicamente humillado, por cuanto debe asumir una nueva responsabilidad en los sectores más húmedos y desolados de las estrechas y oscuras galerías subterráneas. En otras palabras, este anciano ya no presenta la reciedumbre de sus años mozos, cuando como barretero y después como contratista, hundía la barreta a "puño y canto" del "lustroso carbón milenario". Ahora, cuando sus extremidades están en plena declinación, casi en calidad de rastrojo, lo destinan en forma degradante a hacerse cargo de una bomba de agua en lo más recóndito de la oscuridad de la mina, bajo el golfo de Arauco, donde asquerosas y hambrientas ratas son su única compañía. A nivel intertextual, el destino del protagonista de este relato es semejante al que sufre Diamante, el envejecido caballo de "Los inválidos" de Baldomero Lillo, que después de diez años de arrastrar el mineral en el interior de los chiflones, ciego y cojo, es devuelto a la superficie para ser devorado por hambrientos tábanos. Pero el paralelismo de don Pedrito alcanza al viejo Bonnemort ("Buena Muerte"), personaje de la novela Germinal (1885) de Émile Zola (1840-1902), quien trabaja desde los ocho años en el mineral y ahora a los cincuenta y ocho, pese a que esputa sangre y carbón debido a la silicosis que padece, labora en la superficie de la mina La Voreux (situada al norte de Francia), guiando los caballos que arrastran el mineral ${ }^{30}$.

d) Finalmente, el cuento "Tren a Río Pedregoso" (1992) del escritor avecindado en la provincia de Arauco, Miguel Ramírez (1944), forma parte del libro Tren a Río Pedregoso y otros cuentos (1992), reeditado en Antología de Raíces (2001). Ramírez es reconocido por la crítica local por su extensa producción narrativa, prácticamente ininterrumpida desde que surgió su primera novela, Pino grande (1975), hasta su última producción, El centauro de Nahuelbuta (2015). Prácticamente la mayor parte de sus numerosas creaciones están ambientadas en la mágica e impenetrable cordillera de Nahuelbuta.

El relato en estudio actualiza el tema del tren de propiedad de la empresa carbonífera, como espacio de segregación, injusticia y atropello arbitrario, asociado a la "cuestión social". En la primera década del siglo XX, época traducción de la novela, año 1995 (13-22). Al mismo tiempo, esta referencia se complementa con la información proporcionada por el estudioso Jaime Concha (2008), quien al referirse al imaginario minero que ha llegado a través de la literatura y el cine, expresa: "Germinal es la novela emblemática de este universo minero ("tipo ideal" la consideran algunos) y la hemos podido ver, hace apenas unos años, en una nueva versión cinematográfica, con dirección de Claude Berry, protagonizada por el actor Gerard Depardieu (en el papel de Maheu)" (18-19). 
del imperio de la industria carbonífera, el tren de propiedad de la Compañía Arauco era el único medio de locomoción que unía los centros mineros de Curanilahue, Lota y Coronel, con la ciudad de Concepción ${ }^{31}$. Se evidencia en el texto en forma reiterada la acción abusiva de cobranza indebida que sostienen durante el viaje, tanto los inspectores como los cobradores de boleto (empleados de confianza de la empresa) para con los pasajeros de tercera clase (obreros, en su mayoría), y con los protagonistas del relato, Andrés y Donato, dos jóvenes estudiantes, quienes viajan con un propósito familiar hacia Río Pedregoso, ramal "ficticio" de la última Estación de Curanilahue.

\section{LA "CUESTIÓN SOCIAL" EN LA NARRATIVA LOCAL DEL CARBÓN}

La "cuestión social" ha sido estudiada a nivel nacional por reconocidos historiadores como Gonzalo Vial (1987), Sergio Grez (1995), James Morris (2000), Mario Garcés (2004) ${ }^{32}$, entre otros.

En el contexto específico de la zona industrial vinculada a la explotación de los yacimientos carboníferos de la Región del Biobío, los cambios asociados directamente a la "cuestión social" se traducen, de acuerdo a los estudios historiográficos nacionales, mencionados con anterioridad, en los siguientes resultados colectivos:

a) Desplazamiento de población del campo a la ciudad. Este fenómeno demográfico determina la estrecha relación in solidum, entre el campesino y el minero. Además, influye la forma como trascienden los valores sociales y

31 De acuerdo a la información extraída del estudio de Hernán Venegas (1997): La Compañía Arauco, fundada en 1884, estableció los yacimientos de Colico, Plegarias, Carampangue, Moquehua y Curanilahue. Además, “obtuvo la concesión especial para la construcción del ferrocarril de Concepción a Curanilahue, que unió los principales yacimientos carboníferos locales" (132).

32 Mario Garcés (2004) define la "cuestión social" de la siguiente manera: "Una categoría europea con la cual se buscaba nombrar "el problema obrero" [...] Se trató de un doble fenómeno: por una parte, del deterioro de las condiciones de sobrevivencia de la clase popular, y por la otra, de la emergencia de la protesta social obrera encaminada a modificar esa situación de deterioro" (17). 
espirituales arraigados en los personajes de origen campesino, vinculados a la humildad, el respeto, la docilidad, la mansedumbre, etc. ${ }^{33}$.

b) Sentimientos de crisis social y humanitaria, ligada a la miseria y al hacinamiento. El minero y su numeroso grupo familiar recibían como usufructo una vivienda popular. No obstante, cuando el obrero fallecía en el interior de la mina o en la bodega de un barco carbonero (tema abordado a nivel literario en dos obras narrativas de Juan Marín) ${ }^{34}$, para continuar con el usufructo de la pieza, el cumplimiento laboral la asumía en forma obligatoria la esposa (trabajando en la superficie de la mina) o el hijo mayor, en el interior de las galerías, aunque fuere un niño de solo ocho o nueve años.

c) Inquietudes o preocupación por el mejoramiento de los jornales. Se evidencia de a poco la preocupación por la organización entre los obreros, a través de la "Mutual", como el único medio para mejorar las condiciones laborales. También surge en la clandestinidad el panfleto como medio de información sindical.

d) Condiciones de trabajo y pequeños atisbos por la organización del movimiento obrero, etc. Guiados por el líder nacional, Luis Emilio Recabarren, surge a comienzos del siglo XX la Federación Obrera de Chile, más conocida como la $\mathrm{FOCH}^{35}$. De esta forma, se organizan en diversas regiones de Chile congresos de trabajadores.

Otros dos factores importantes asociados a la "cuestión social" de la zona carbonífera son los siguientes: "La ignorancia y despreocupación por la instrucción de los hijos" y "El alcoholismo y la prostitución causadas por la mala calidad de vida". Sin embargo, estas situaciones no serán consideradas en este artículo, por estar ausentes en las obras en estudio.

33 Gregorio Corvalán complementa esta hipótesis cuando afirma: "Los primeros mineros campesinos que a mediados del siglo pasado trocaron la luminosidad de los campos por la oscura miseria del fondo de la mina, iniciaron sus nuevas labores 'con lo puesto' (míseras ojotas, raídos pantalones y camisas y chupallas), sumándose a este precario vestuario la menos precaria iluminación de pequeñas lámparas de lata que se fijaban a la chupalla (19).

34 Juan Marín escribió dos obras narrativas centradas en la explotación carbonífera: el cuento Puerto negro (1938) y la novela Viento negro (1960).

$35 \quad$ Alejandro Witker en su libro Los trabajos y los días de Recabarren (1977) analiza en profundidad la vida del líder sindicalista, en el contexto de la conmemoración en 1976 del centenario del fundador del movimiento obrero chileno. 
3.1. Últimamente, Laura Benedetti (2011), plantea esta importante temática a nivel de los yacimientos carboníferos de Coronel y Lota. El estudio historiográfico de Benedetti se centra en el poder económico de los propietarios de las minas, poder que se extendió hacia el conjunto total de las actividades ligadas al carbón: como el precio en el transporte (ferrocarril y barcos); los mecanismos de dominación como la quincena; el control de la justicia a través de la policía privada; los medios de pago como las fichas; la asignación de viviendas populares, etc. En ese contexto de presión social, surgen paulatinamente acciones de luchas reivindicativas, como el motín, primera medida de protesta; las huelgas, como estrategias más organizadas y las comisiones negociadoras, que se manifiestan en el corpus de obras literarias seleccionadas como "dolencias colectivas" 36 , las que trajeron grandes transformaciones a nivel económico, social y político, especialmente en las primeras décadas del siglo XX.

3.2. Ahora bien, a nivel de análisis de las temáticas de la "cuestión social en las obras en estudio, se consideran cinco factores relevantes que se evidencian plenamente en las páginas de los textos, especialmente en las novelas:

a) Abusos, actos de injusticia y presiones como "dolencias colectivas". Guillermo Pedreros describe estas acciones degradantes que ejerce la policía particular contra los líderes sindicales y los mineros que participan en el movimiento huelguístico. Destaca a la policía como un organismo dependiente de los dueños del mineral y, por lo tanto, solo se adscriben a las órdenes de los administradores y capataces de los yacimientos: "La Compañía tenía en los minerales una Policía Particular (sic) que no obedecía otras leyes que la de sus amos [...] comete toda clase de depredaciones en las personas y en las cosas" (19).

Las personas que integran este organismo policial son principalmente criminales venidos desde fuera. La empresa minera -recalca Pedreros- les otorga a estos bandoleros poder, a cambio del orden y la sumisión que obtienen de los mineros, mediante el uso excesivo de la violencia: “....son acompañados por Hermenegildo Urrea, conocido [...] como un criminal en la huelga que hubo en 1916 en donde asesinó a varios compañeros [...]. Se han contratado varios rompehuelgas llevados desde Concepción..." (54) 
Por otra parte, manifiesta el escritor-dirigente que el objetivo de los empresarios es acallar las justas protestas "de quienes están siendo víctimas por tantos años de la más brutal explotación, con prisiones, fuerza armada, procesos, etc." (57). Así, la violencia y los abusos que pueden ejercer las fuerzas públicas llegan a tal extremo que destruyen hasta los alimentos que fueron donados por organizaciones sociales del país:

Aparece un destacamento de carabineros al mando de un oficial $[\ldots]$ se dirigió hacia el lugar donde funcionaba la cocina de la olla común, dando vuelta los fondos con comida al mar, para luego hacer lo mismo con los sacos de azúcar, café [...] y con todos los alimentos que habían acumulado [...] para las comidas de los trabajadores en huelga..." (95-96)

A nivel de actos de injusticia y discriminación, un ejemplo representativo se encuentra en "Tren a Río Pedregoso" (analizado más arriba), donde la prepotencia de los gerentes es traspasada a los cobradores, empleados corruptos de la Compañía Arauco, propietaria del tren que une Concepción con Curalinahue, pasando por los centros mineros de Coronel y Lota. Al mismo tiempo, la distribución de los pasajeros en los carros era un ápice de la pirámide social, que imperaba en esas ciudades industriales. Un buen ejemplo intertextual lo encontramos en la novela Tiempo de arena de Julio Aldebarán ${ }^{37}$, donde se describe un viaje entre Coronel y Concepción:

En primera viajaban los altos empleados de la compañía minera y sus familiares, la aristocracia de Concepción, el Gobernador con pasaje libre y uno que otro representante de la clase alta comercial coroneliana. En segunda, con asientos de cuero negro se acomoda la típica clase media, principales empleados públicos del puerto, vendedores viajeros de las más conocidas casas comerciales del país y las familias de los capitanes de barco. Nadie puede pasar de segunda a primera $[\ldots]$ Los carros de tercera son tres o cuatro, en ellos viajan los comerciantes árabes de boliche, los mineros y las prostitutas, tienen asiento de madera y atmósfera olorosa a letrinas atascadas... (108)

37 Obra un tanto desconocida de Julio Aldebarán (seudónimo del ingeniero civil, Gustavo Possel Méndez), ambientada en el puerto de Coronel en su época esplendorosa (1914-1940). 
b) Desplazamiento de población del campo a la ciudad. Este fenómeno demográfico asociado a la "cuestión social" se evidencia con mayor nitidez en Hijo de las piedras, ambientada en el mineral de Lota de comienzos del siglo XX. Juan Sánchez expresa que el traslado obligado de las familias del campo a la ciudad se produce por circunstancias propias del avasallamiento de la industrial carbonífera, como es la compra forzada de terrenos en los sectores aledaños a los centros mineros, destinados a la plantación de pinos, para fortificación de las galerías subterráneas. La madre del niño protagonista de la novela lamenta esta situación de desarraigo producida por la empresa:

Tu padre tampoco nació en el mineral, hijo mío; era agricultor [...] Vivíamos felices trabajando bien la tierra propia. Teníamos de todo en nuestra casa. Éramos libres [...] La casa nuestra era grande. Tú no te acordarás de nada; cumplías dos años. Esa gente del campo no es triste como nosotros [...]. Ahora esa región está cubierta de bosques, soledad, sombras y silencio (30-33).

c) Sentimientos de crisis social y humanitaria, ligada a la miseria y al hacinamiento. En la novela del minero lotino, el niño protagonista recuerda con nostalgia su agobiado pasado infantil:

A los ocho o nueve años, con raras excepciones, los niños dejaban de jugar y de reír [...] A mí el destino me deparaba, además, otras sorpresas: lo bueyes murieron y nos arruinaron, como en juego de azar, en un momento [...] Sin la yunta en trabajo, pronto llegó de nuevo la orden de desalojo. Vi salir a mi madre hacia la administración del establecimiento, dolorosamente resignada, como se acepta todo lo irremediable: un incendio, un terremoto o la muerte (73-74).

Pero la situación de angustia y miseria para el niño Omar de solo ocho años es peor; pronto pierde a su madre y a su abuela, quedando solo en el mundo. Trabaja primero, junto a otros niños huérfanos (tema recurrente en la literatura del carbón), en las plantaciones de pino y, posteriormente, gracias al apoyo de un "Padrino", ingresa a la mina de Lota.

d) Inquietudes o preocupación por el mejoramiento de los jornales, cancelados con fichas. En el texto de Sánchez Guerrero surge esta inquietud asociada a los jornales y los abusos en las condiciones de trabajo solo a nivel de personajes secundarios. En primer lugar, en la voz clandestina de don Remigio, "el panfletero", exminero conocido en Lota como vendedor 
de moluscos y de pescado, pero que en forma encubierta porta en su canasto las informaciones de la "Mutual", recién fundada en Coronel:

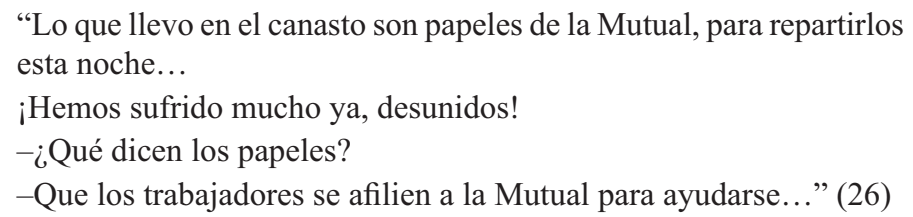

En segundo lugar, y nuevamente a nivel de personaje secundario, en el capítulo XII de la novela de Sánchez Guerrero, aparece una segunda voz, la de don Jesús, un español dueño de un emporio en Lota. Este comerciante manifiesta con franqueza que los obreros de las minas solo mejorarán las condiciones de trabajo y conseguirán mejores jornales cuando logren organizarse a través de un líder; dice:

\begin{abstract}
"-iAh! Es que en ustedes existe un problema más hondo. Yo también fui obrero en mi país y los entiendo. En primer término ustedes beben demasiado, y no se unen ${ }_{i}$ Eso es! ¡No se unen! [...] Mientras ustedes permanezcan desunidos, despreocupados, callados, todos nos aprovechamos y enriquecemos [...] Yo converso a menudo con un compañero de ustedes. El "Amigo", que le dicen. Ese hombre está empeñado en algo. Algo resultará. Únanse” (163).
\end{abstract}

Es decir, a juicio del español, el "Amigo" (Sebastián Mercado, admirado por grandes y chicos por su fortaleza física y por su generosidad, tutor de Omar, el desamparado niño protagonista, y protector de las demás criaturas que con ojotas trabajan en el fondo del yacimiento), es el único obrero capaz de visualizar que solo el camino de la coalición y la organización gremial les permitirá lidiar contra los abusos y las injusticias laborales y sociales.

e) Pequeños atisbos por la organización del movimiento obrero, en pro de mejores condiciones de trabajo, considerando los salarios exiguos, agotadoras jornadas de trabajos y abusos de la policía particular.

En la obra de Guillermo Pedreros se identifica a la Revolución de Octubre (o Revolución Bolchevique, acontecida en el año 1917, que pone fin a la última monarquía zarista de Rusia ), como el hito que permite a los mineros asumir una posición dirigente y no comprender su realidad en torno a su mera producción. Por ello se destaca que debe ser creada en Lota y Coronel un respectivo Consejo Local de la Federación Obrera de Chile (FOCH), 
organismo que les permitiría construir una organización cohesionada y que unificaría sus demandas a través del sindicalismo.

Dicha organización plantea varios mecanismos para el funcionamiento de la huelga. Uno de los principales es politizar a grandes cantidades de personas: "sujeto colectivo" o, en palabras de Alain Touraine, 'actor colectivo': "cuya orientación principal es la defensa del sujeto, la lucha por los derechos y la dignidad de los trabajadores" $(237)^{38}$. Un factor clave se circunscribe al involucramiento de todas las familias mineras en la huelga. Para ello -expresa Pedreros-, mujeres como Emperatriz Márquez intentan instaurar un cambio cualitativo de las conversaciones que tenían las mujeres en los tradicionales espacios comunes: los lavaderos y los hornos, destinados a cocer el pan minero.

Conversarían con sus maridos, con sus hermanos [...] con sus parientes para convencerlos en la necesidad de tener una actitud solidaria con los obreros de Lirquén, Penco y Curalinahue. Luchar por mejores salarios, jornada de ocho horas de trabajo, mejores viviendas, más escuelas y desaparición de la Policía Particular (sic), en fin, luchar por una vida humana (39).

Pero como los obreros no se decidían, fue necesario una segunda acción femenina, conocida como la "Rebelión de las cocinas" (47), la que terminó por vencer algunos escrúpulos que detenían la decisión de luchar de los mineros, en el movimiento huelguístico.

En la misma novela, otras acciones asociadas a los "actores colectivos" están relacionadas con las numerosas reuniones o concentraciones en el Estadio de Lota (anfiteatro natural), donde acudían los mineros, sus mujeres y sus hijos (todos juntos, en los triunfos y en las derrotas), a recibir informaciones y noticias del movimiento huelguístico, que se dilataba en el tiempo, por la tozudez de las autoridades y la insensibilidad de los administradores. Siempre estas reuniones masivas eran convocadas por Miguel ("el corneta"), joven huérfano, de origen prácticamente desconocido, que tocaba el cuerno (o cacho de buey), siguiendo las instrucciones de los líderes sindicales.

Además, en el contexto de las reuniones masivas se destaca la dirección efectiva del movimiento, donde los oradores de la FOCH instruían a los mineros sobre la importancia de mantener la unidad para lograr el triunfo; al mismo tiempo, se hacía hincapié, aparte de los míseros salarios y extensas 
jornadas de trabajo, en las condiciones paupérrimas de vida a las que estaban sometidos (miserables habitaciones) y las complicaciones morales que traía consigo el hacinamiento, contrastando la miseria obrera con la opulencia de los patrones.

Otros métodos y recursos a los que recurren los huelguistas para mantener la unidad: 1) Las técnicas promovidas por Luis Emilio Recabarren, relacionadas con la creación de una prensa que permita enseñar, dirigir a las masas de los trabajadores de la región y del país. 2) Los discursos, la poesía y el canto son otros mecanismos que la FOCH y el Colectivo Artes y Emancipación mantienen recurrentes en el modo de organización, que se repite a lo largo de toda la obra.

Finalmente, la organización obrera celebra el primero de mayo, Día del Trabajador, con súbita alegría, pues, triunfa la huelga (Ver cap. "La Gran Victoria"). Vuelven las familias mineras que han sido enviadas a Concepción. Por la tarde, suena la corneta que reúne a la gente en la cancha de fútbol para una asamblea de la FOCH. La tribuna está adornada de copihues en atención a los logros colectivos alcanzados por la comisión negociadora, esto es, reducción a ocho horas de trabajo, eliminación de la policía privada y aumento salarial. Sin embargo, la organización aún se proyecta, los esfuerzos de Delfina González - concluye Pedreros- permiten la creación del "Consejo Federal Femenino $\mathrm{N}^{\mathrm{o}} 1$ de la Federación Obrera de Chile, al cual pueden pertenecer todas las mujeres con ansias de un futuro mejor" (122).

La obra de Pedreros finaliza con las exequias y homenaje póstumo a Delfina González, líder admirable "en cuya historia podrán encontrar las mujeres [trabajadoras] de hoy, el ejemplo, para imitarla y contribuir al triunfo de la clase obrera" (127).

\section{CONCLUSIONES}

1) En los relatos de Baldomero Lillo, Sub terra, todavía no se evidencia la denuncia colectiva y social de los trabajadores de los yacimientos carboníferos; en otras palabras, no existe un referente asociado a la organización sindical obrera. Además, los movimientos políticos ni siquiera existían cuando se publican los episodios de "La compuerta número 12".

2) Los escritores posteriores a Lillo, algunos de ellos en su condición de mineros o de dirigentes sindicales, producto de la invención de la memoria, 
de la invención de un pasado, ponen en evidencia a través de la literatura temas asociados a la "cuestión social", a la presencia de la organización obrera y a la rememorada protesta gremial (huelga de 1920).

3) La dos novelas analizadas se inscriben en las modalidades discursivas de la memoria: Una huelga en el carbón se asienta sobre hechos sociohistóricos ligados a los centros mineros de la Región del Biobío. El autornarrador procede a la narrativización de una experiencia real, posible de someter a pruebas de veredicción. Entendida esta última como referida a acontecimientos que han ocurrido, en sentido estricto en la vida social, laboral y sindical; por lo tanto, tienen existencia fuera del discurso. Pero también se evidencian elementos metafóricos, narraciones subjetivas y presencia de textos complementarios (canciones, noticias, telegramas, etc.) que lo acercan al texto literario. Por su parte, Hijo de las piedras es un discurso que apela a la autobiografía, por cuanto aborda, evoca, interpreta y reproduce, desde la perspectiva del yo, capítulos sobre circunstancias de una historia de niñez individual, determinada por quiebres o situaciones límite, a los cuales el narrador-personaje se ve sometido.

4) En las páginas de los textos ficcionales, me refiero especialmente a los cuentos, se describen en forma despiadada y estremecedora imágenes del mundo deshumanizado, que abarca tanto el trabajo minero como el espacio familiar, donde prima el abuso de poder, la injusticia y la miseria.

5) En esta narrativa del carbón de mediados del siglo $X X$ imperan algunos rasgos característicos: ausencia de individuación; sujetos colectivos unidos por una causa social; actores sociales (líderes masculinos y femeninos); la mujer menoscabada; el niño-hombre, apoyado por un padrino; presencia de fuerzas hegemónicas (el gerente, el capataz, el mayordomo, la policía privada, el cobrador del tren) y espacios de segregación social (la habitación del minero y el ferrocarril de la compañía).

6) Este artículo se inscribe, en palabras de Rodrigo Cánovas ${ }^{39}$, en un círculo crítico vinculado a la reflexión sobre literatura y sociedad en la zona de las minas del carbón de la Región del Biobío, de mediados del siglo XX. Es decir, podemos evidenciar que estamos frente a otro circuito de literatura (otras voces narrativas o novelísticas), que tiene intenciones de denuncia social, de testimonio social. 
7) Finalmente, este artículo es parte de un proyecto mayor (por cuanto no considera la narrativa de reconocidos escritores nacionales, posteriores a Baldomero Lillo), que tiene como objetivo rescatar estas obras literarias desconocidas, que evidencian la miseria, el hacinamiento y las demandas de los trabajadores de los centros carboníferos, de comienzos y mediados del siglo XX, con el fin de seleccionarlas, analizarlas y divulgarlas con una visión macroestructural del discurso social, laboral y sindical. De esta manera, se retomará el objetivo de sus creadores: utilizar la función de la literatura en su dimensión extratextual, relacionarla con el público, con la historia y con la sociedad. En otras palabras, la narrativa es un complejo sistema de relaciones discursivas que no siempre encuentra lecho en los quisquillosos límites de las taxonomías literarias. Los márgenes más producen textos que desafían los cánones y enriquecen la historia literaria.

\section{BIBLIOGRAFÍA}

Alcalde, Alfonso. Reportaje al carbón. Santiago: Editora Nacional Quimantú, 1973. "El ratón de cada uno". Alfonso Alcalde en cuento. Antología. Ed. Jorge Ramírez. Concepción: Editorial El Árbol de la Palabra, 1992. 167-176. 2007.

Aldebarán, Julio. Tiempo de arena. Santiago: Universitaria, 1981.

Álvarez, Ignacio. "Huérfanos y mineros: Notas para la evaluación de la estrategia representativa del obrero en los cuentos de Baldomero Lillo". Anales de la Literatura Chilena 14, Año 11 (2010): 93-116.

Bahamonde, Juan. "Voces míticas en la zona chilena del carbón. Relaciones entre el mundo minero y el mundo literario". Literatura, arte y discurso crítico en el siglo XXI. Vol. 3. Coord. Arturo Morales y Francisco Larios. México: Facultad de Lengua y Literatura Hispánicas UMSNH, 2013. 195-212.

"Voces míticas gestadas en la sombra de las minas del carbón: un enfoque semiótico". ALPHA 37 (2013): 59-78.

Benedetti, Laura. La cuestión social en Concepción y los centros mineros de Coronel y Lota (1885-1910). Tomé: Ediciones Al Aire Libro, 2011.

Cánovas, Rodrigo. Novela chilena nuevas generaciones. El abordaje de los huérfanos. Santiago: Ediciones Universidad Católica de Chile, 1997.

Carrasco, Iván. "Literatura chilena: canonización e identidades". Estudios Filológicos 40 (2005): 29-48. 
Concha, Jaime. "Lillo y los condenados de la tierra". Obra completa. Eds. Ignacio Álvarez y Hugo Bello Maldonado. Santiago, Chile: Ediciones Universidad Alberto Hurtado, 2008. 15-67.

Contreras, Marta, et al. José Chesta. Textos y Contextos. Concepción: Ediciones Universidad de Concepción, 1994.

Corvalán Basterrechea, Gregorio. Gente del carbón (Kuyulche).Concepción: Ediciones Letra Nueva, 1990.

Fierro, Juan Manuel. "El discurso de la memoria en Chile (1970-2005)". Tesis Doctoral. Universidad Austral de Chile, 2005.

Garcés, Mario. "Los movimientos sociales populares en el siglo XX: Balance y perspectivas". Política 43 (2004): 13-30.

Goic, Cedomil. "La novela chilena actual. Tendencias y Generaciones". Anales de la Universidad de Chile (1960): 250-258. $3^{\mathrm{a}}$ edición.

Gómez, Víctor Hugo. “Trasto viejo”. Antología del cuento minero chileno. Coord. Javier Jofré. Santiago: Editorial Universitaria, 1991. 301-305.

Grez, Sergio. La “cuestión social” en Chile. Ideas y debates precursores (1804-1902). Santiago: Imprenta Biblioteca Nacional, 1997: 6-44. Recuperado de: http://www.memoriachilena. cl/archivos2/pdfs/MC0005041.pdf

"Transición en las formas de lucha: motines peonales y huelgas obreras en Chile (1891-1907)". Historia. Vol. 33. Santiago: Memoriachilena. Biblioteca Nacional de Chile, 2000. 1-68

Los anarquistas y el movimiento obrero. La alborada de "la Idea" en Chile, 18931915. Santiago: LOM Ediciones, 2007.

Guzmán, Nicomedes. Antología de Baldomero Lillo. Santiago: Zig-Zag, 1954.

Latorre, Mariano. "El finado Valdés". Chile, país de rincones. Tomo 3. Santiago: Editorial Universitaria, 1987. 12-42.

Marín, Juan. Puerto negro. Santiago, diario “El Mercurio”, domingo 9 de enero, 1938.

Viento negro. Santiago: Zig-Zag, 1960.

Morales Carrasco, Felipe. "La ficcionalidad literaria de la "Huelga grande del carbón de 1920" en Diego Muñoz y Guillermo Pedreros". Tesis Pedagogía en Castellano y Comunicación. Universidad del Bío-Bío, Facultad de Educación y Humanidades, 2016.

Morales, Leonidas. La escritura de al lado: géneros referenciales. Santiago: Editorial Cuarto Propio, 2001.

“Géneros referenciales: identidad y comunidad”. Nomadías 11 (2010): 123-129.

"Memoria y géneros autobiográficos". Anales de Literatura Chilena 19 (2013): 13-24.

Morris, James. "Las élites, los intelectuales y el consenso". Estructura social de Chile. Godoy, Hernán. Santiago: Editorial Los Andes, 2000. 234-254.

Narváez, Jorge. "El estatuto de los textos documentales en América latina”. La invención de la memoria (Actas). Santiago: Editorial Universitaria, 1988. 
Pedreros, Guillermo. Una huelga en el carbón. Santiago: Cepeda y Rodríguez, 1965. Huenchupil agitador profesional. Santiago: Prensa Latinoamericana, 1970.

Ramírez, Miguel. “Tren a Río Pedregoso”. Antología de raíces. Santiago: Editorial Génesis, 2001. 322-360.

Rojas Flores, Jorge. "Trabajo infantil en la minería”. Apuntes históricos, Historia Vol. 32 (1999): 396-406.

Sánchez Guerrero, Juan. Hijo de las piedras. Santiago: Zig-Zag, 1963.

Touraine, Alain. Crítica de la modernidad. Buenos Aires: Fondo de Cultura Económica, 2000, sexta reimpresión.

Venegas Valdebenito, Hernán. "Crisis económica y conflictos sociales y políticos en la zona carbonífera. 1918-1931”. Contribuciones científica y tecnológicas. Área Ciencias Sociales y Humanidades 116. Santiago: Universitaria, 1997. 125-153. Recuperado de: http://www. memoriachilena.cl/602/w3-article-70888.html

Witker, Alejandro. Los trabajos y los días de Recabarren. México: Editorial Nuestro Tiempo, 1977.

Zola, Émile. Germinal. Barcelona: Olympia Ediciones, 1995. 